Review

\title{
Verotoxin-1 Treatment or Manipulation of its Receptor Globotriaosylceramide (Gb3) for Reversal of Multidrug Resistance to Cancer Chemotherapy
}

\author{
Parviz Behnam-Motlagh ${ }^{1}$, Andreas Tyler ${ }^{1}$, Kjell Grankvist ${ }^{1}$ and Anders Johansson ${ }^{2, *}$ \\ 1 Department of Medical Biosciences, Umeå University, S-901 85 Umea, Sweden; \\ E-Mails: parviz.behnam@medbio.umu.se (P.B.-M.); andreas.tyler@medbio.umu.se (A.T); \\ kjell.grankvist@medbio.umu.se (K.G.) \\ 2 Department of Odontology, Umeå University, S-901 85 Umea, Sweden \\ * Author to whom correspondence should be addressed; E-Mail: anders.johansson@odont.umu.se.
}

Received: 19 September 2010; in revised form: 15 October 2010 / Accepted: 19 October 2010 / Published: 25 October 2010

\begin{abstract}
A major problem with anti-cancer drug treatment is the development of acquired multidrug resistance (MDR) of the tumor cells. Verotoxin-1 (VT-1) exerts its cytotoxicity by targeting the globotriaosylceramide membrane receptor (Gb3), a glycolipid associated with multidrug resistance. Gb3 is overexpressed in many human tumors and tumor cell lines with inherent or acquired MDR. Gb3 is co-expressed and interplays with the membrane efflux transporter P-gp encoded by the MDRl gene. P-gp could act as a lipid flippase and stimulate Gb3 induction when tumor cells are exposed to cancer chemotherapy. Recent work has shown that apoptosis and inherent or acquired multidrug resistance in Gb3-expressing tumors could be affected by VT-1 holotoxin, a sub-toxic concentration of the holotoxin concomitant with chemotherapy or its Gb3-binding B-subunit coupled to cytotoxic or immunomodulatory drug, as well as chemical manipulation of Gb3 expression. The interplay between Gb3 and P-gp thus gives a possible physiological approach to augment the chemotherapeutic effect in multidrug resistant tumors.
\end{abstract}

Keywords: apoptosis; cancer; Gb3; verotoxin-1; multi-drug resistance; $M D R 1$; P-gp 


\section{Shiga Toxins}

The Shiga toxin family, a group of related exotoxins, includes Shiga toxin from Shigella dysenteriae and Shiga toxins such as verotoxin-1 (VT-1, Shiga-like toxin-1) produced by pathogenic strains of Escherichia coli $[1-3]$.

VT-1 consists of one A and five B subunits. The B subunit binds to the neutral glycosphingolipid cell surface receptor globotriaosylceramide (Gb3) [4,5] and is endocytosed. The toxin then follows the retrograde pathway to the endoplasmic reticulum where the A-subunit is translocated to the cytosol and inhibits protein synthesis [6-12].

VT-1 also induces apoptosis through sequential activation of caspases, leading to nuclear changes, such as chromatin condensation and DNA fragmentation. VT-1-induced apoptosis in monocytic THP1 cells requires retrograde transport through the Golgi apparatus to the ER and the activation of caspase-3, the executioner caspase [13]. Similar apoptotic signaling pathways are triggered by Shiga toxins in different cell lines.

VT-1 induces a prominent ribotoxic stress signaling response leading to disrupted ribosomal RNA (rRNA) functions, protein synthesis inhibition and altered mitogen-activated protein kinase (MAPK) pathway signaling [14]. We found that MKK3/6 and JNK was phosphorylated after cisplatin treatment in the cisplatin-sensitive malignant pleural mesothelioma (MPM) cells, but not in the corresponding sub-lines with acquired-cisplatin resistance. VT-1 induced phosphorylation of MKK3/6, which was enhanced when VT-1 was combined with cisplatin [15]. MKK3/6 is known to activate P38 [16,17]. P38, as well as JNK, has been shown to promote apoptosis in response to cellular stress [18]. Treatment of cells with chemical inhibitors or siRNA targeting P38 was recently shown to specifically inhibit VT-1 transport to the Golgi apparatus complex and reduce VT-1 toxicity [19], and VT-1 prolonged JNK and P38 MAPK activation of macrophage-like cells [20]. We have previously demonstrated JNK phosphorylation in response to VT-1 treatment also in glioma and breast cancer cell lines [21,22].

Apoptosis induced by VT-1 was associated with enhanced expression of the pro-apoptotic protein Bax [23] and overexpression of Bcl-2 protects cells against VT-1-induced cell death [24]. Shiga toxins also inhibit the expression of the anti-apoptotic Bcl-2 family member Mcl-1 [25]. Interestingly, acquisition of cisplatin resistance in MPM cells decreased cisplatin activation of the proapoptotic proteins of the Bcl-2 family of proteins [26] and increased the expression of apoptosis inhibitor proteins [27].

\section{Glycosphingolipids and Globotriasosylceramide (Gb3)}

Glycosphingolipids (GSLs) are components of all vertebrate cells and play a fundamental role during development and cell differentiation [28]. GSLs are involved in cellular growth [29], signal transduction [30] and cell-cell interaction [31]. GSL profiling indicates that neutral globo series GSLs (including Gb3) have important roles in mediating MDR1 transactivation and expression [32]. Deletion of $\mathrm{Gb}_{3}$ synthase needed for Gb3 synthesis renders mice completely resistant to VT-1 and VT-2 [33] and GSLs are the only functional VT-1 receptors [34].

GSLs in cells are clustered and assembled with specific membrane proteins and signal transducers to form GSL-enriched microdomains or lipid rafts [35-37]. Rafts are rich in GSLs, cholesterol, 
lipid-modified- and transmembrane proteins [38]. The length of the fatty acyl chain of Gb3 influences its receptor function, intracellular sorting and retro-translocation of VT-1 to the cytosol $[39,40]$. Binding of VT-1 B-subunit with clustered raft-localized Gb3 receptors [41] is a requirement for the retrograde transport [42] and for a cytotoxic effect in the ER [43]. For cells with $\mathrm{Gb}_{3}$ present in the non-raft plasma membrane fraction, the toxin receptor complex is internalized and trafficked to lysosomes where the toxin is degraded, leading to VT-1 resistant cells. [44]. Furthermore, VT-1 B subunit binding to Gb3 induces lipid reorganization of the cell membrane leading to enhancement of VT-1 uptake into the cell [45].

$\mathrm{Gb}_{3}$ membrane organization also plays a central role in determining in vivo sensitivity to verotoxin-induced glomerular pathology of hemolytic uremia syndrome (HUS). $\mathrm{Gb}_{3}$ is distributed throughout the human nephron but only the Gb3 of the glomeruli is localized to lipid rafts making glomeruli sensitive to the cytopathology of systemic VT-1. The membrane organization of the glycosphingolipid receptor is the main discriminator for pathology in vivo [34,46].

The expression and metabolism of cell surface glycolipids is changed during oncogenic transformation and altered glycosylation patterns affect tumor invasion and metastasis [37]. $\mathrm{Gb}_{3}$ is expressed in several human malignancies including breast cancer [22] and testicular carcinoma [47]. $\mathrm{Gb}_{3}$ expression has been detected in lymphoma [48] and in various solid tumors [49]. $\mathrm{Gb}_{3}$ expression in colorectal cancer correlates with invasiveness and metastatic potential [50]. Elevated levels of Gb3 have also been seen in drug-resistant cancers and cell lines and a functional interplay between membrane Gb3 and MDR1 has been suggested [51,52]. These findings suggest that the Gb3-binding specificity of VT-1 could be used to target tumors in the receptive cancer cells.

\section{Multidrug Resistance to Cancer Chemotherapy}

Poor response to cancer chemotherapy is usually due to drug resistance [53,54]. In breast cancer alone, nearly $50 \%$ of patients demonstrate primary and/or secondary resistance to doxorubicin [55].

Tumor overexpression of the membrane efflux transporter P-glycoprotein (P-gp) is a common alteration in drug resistance [53,54,56]. P-gp, encoded by the $M D R 1$ gene [57], was the first $\mathrm{ABC}$ protein demonstrated to confer resistance to cancer chemotherapeutics [58,59]. Other transporter proteins such as multidrug resistance protein (MRP1) and breast cancer resistance protein (BCRP) have also been described. P-gp plays roles in the absorption, distribution and excretion of compounds in normal tissues. Overexpression of $M D R 1$ in tumors results in active efflux of several types of anticancer agents. P-gp is expressed by many types of primary solid tumors such as breast, colon, renal, and ovarian cancers, as well as hematological malignancies such as acute myeloid leukemia and non-Hodgkin's lymphoma [60].

Exposure to chemotherapy can up-regulate tumor P-gp expression, which occurs in acquired drug resistance [61] and severely limits the success of chemotherapy [54,62]. In small cell lung cancer, acquired resistance to multiple drugs is responsible for a chemotherapeutic cure rate below 10\% [63]. In breast cancer, 55\% of the tumors expressed P-gp 55\% before and 100\% after chemotherapy [64]. MDR1 inhibitors have been clinically tested in order to block drug efflux. Specific modulators or inhibitors such as GG918 and LY335979 have overcome the toxic adverse effects noted in first generation modulators but still have minor effect when co-administrated with chemotherapeutics in trials [65,66] in part due to MDR1 polymorphisms [32]. 


\section{Globotriasosylceramide (Gb3) and MDR1 Expression}

Little is known about the molecular mechanism underlying MDRl overexpression and how it interacts with other genes to impart drug-resistance. Overexpression of glucosylceramide synthase (GCS), the first enzyme of GSL synthesis, can result in multidrug resistance. Many cells expressing MDR1 show elevated levels of glucosylceramide (GlcCer) [67,68], and inhibitors of GCS kill MDR cells [69]. MDR1 can translocate glucosylceramide into the Golgi apparatus for neutral GSL synthesis, including Gb3. P-gp has been proposed as a Golgi glucosylceramide flippase that enhances neutral GSL synthesis as transfection of MDRl increases, and inhibition of P-gp decreases neutral GSL biosynthesis in cells [70]. GCS up-regulates MDR1 expression and modulates drug resistance of cancer.

Partial MDR1 and $\mathrm{Gb}_{3}$ cell surface co-localization has been observed and inhibition of GSL biosynthesis depletes cell surface MDR1. MDR1 may therefore interact with $\mathrm{Gb}_{3}$. A significant fraction of surface MDR1 is not co-localized with $\mathrm{Gb}_{3}$, and could therefore be VT-1-insensitive. MDR1 can be expressed in cells lacking $\mathrm{Gb}_{3}$. However, drug-resistant metastatic ovarian tumor cells have a particularly high $\mathrm{Gb}_{3}$ content [49] and $\mathrm{Gb}_{3}$ is highly expressed in metastatic colon carcinoma [50].

The water-soluble $\mathrm{Gb}_{3}$ mimic adamantylGb 3 , but not other GSL analogs, reversed MDR1-MDCK cell drug resistance [51]. Verotoxin-mediated $\mathrm{Gb}_{3}$ endocytosis also up-regulated total MDR1 and inhibited drug efflux [71].

The Gb3 content, which is regulated by the expression of Gb3 synthase, was demonstrated to determine the sensitivity of HeLa cells toward VT-1 [72]. We recently demonstrated extensive variability in breast cancer cell lines for apoptosis induction by VT-1. Sensitivity was correlated with Gb3 expression, and use of the drug PPMP, which down-regulates glucosylceramide production, inhibited VT-1-mediated apoptosis [22]. Verotoxin-1 has shown efficacy against meningioma, astrocytoma and renal tumor xenografts in mice [73-75].

\section{Tumor Targeting}

The possibility that VT-1 through the A-subunit could cause protein synthesis inhibition and induce apoptosis in normal cells constitutes a concern for the use of the holotoxin as an anticancer agent. The non-toxic VT-1 B subunit is stable at extreme $\mathrm{pH}$, resists proteases, crosses tissue barriers, distributes in the organism and generally resists extra- and intracellular inactivation [76]. The receptor selectivity of the B subunit has therefore been used to couple it to cytotoxic compounds such as the topoisomerase I inhibitor SN38 [77] or induce an immune response [78] with preferential effects on cancer cells.

Of primary cultures of gastrointestinal tumors, $80 \%$ were found to bind the VT-1 B subunit and could be detected on tumor cells after five days. The stable association of VT-1 B subunit with cells might be a useful property for diagnostic or therapeutic delivery strategies. This subunit has little immunologic properties [79] and is well tolerated in a mouse model [44].

An apparent treatment possibility to reverse MDR is to inhibit GSL biosynthesis by inhibiting GCS or Gb3 synthase enzyme expression and/or activity, or use Gb3 mimics like adamantylGb 3 [51]. 
The treatment obstacle of acquired-cisplatin resistance in malignant plural mesothelioma (MPM) and other cancers makes it necessary to find new strategies to overcome resistance. We showed that cisplatin can up-regulate Gb3 expression in MPM and NSCLC cells and thus sensitize the cells to VT-1-induced cytotoxicity (Figure 1). The increased proportion of Gb3-expressing cells after cisplatin treatment suggests that cisplatin induces Gb3 expression in cancer cells, that cisplatin preferentially eradicates cell with low Gb3 expression and that Gb3 expression is linked to acquired cisplatin-resistance [15]. We could also correlate increased expression of Gb3 in cisplatin-resistant MPM and NSCLC cells to increased expression of MDR1/PgP. PPMP reduced Gb3 expression in resistant sub-line cells and particularly of the Gb3-expressing fraction that was induced when the mother cell line was made cisplatin-resistant. A strong super-additive effect of combined cisplatin and a sub-toxic concentration of VT-1 in cisplatin-resistant malignant pleural mesothelioma cells were observed, indicating a new potential and urgently needed clinical treatment approach [15].

Figure 1. Flow cytometry analysis of membrane bound Gb3 expression by cultured cisplatin-resistant (res) and non-resistant malignant pleural mesothelioma cells (P31) and non-small cell lung cancer cells (H1299) not incubated with and cells incubated for $72 \mathrm{~h}$ with $5 \mathrm{mg} \mathrm{L}^{-1}$ cisplatin or $0.1 \mu \mathrm{g} \mathrm{L}^{-1} \mathrm{VT}$-1, respectively. The percentage of Gb3-expressing cells is noted in the right quadrant in each dot plot. Blank shows unspecific secondary antibody binding, whereas control shows cells not incubated with either cisplatin or VT-1. Cisplatin resulted in further enhanced Gb3 expression, while VT-1 treatment resulted in a complete eradication of the Gb3 expressing cell population [15].

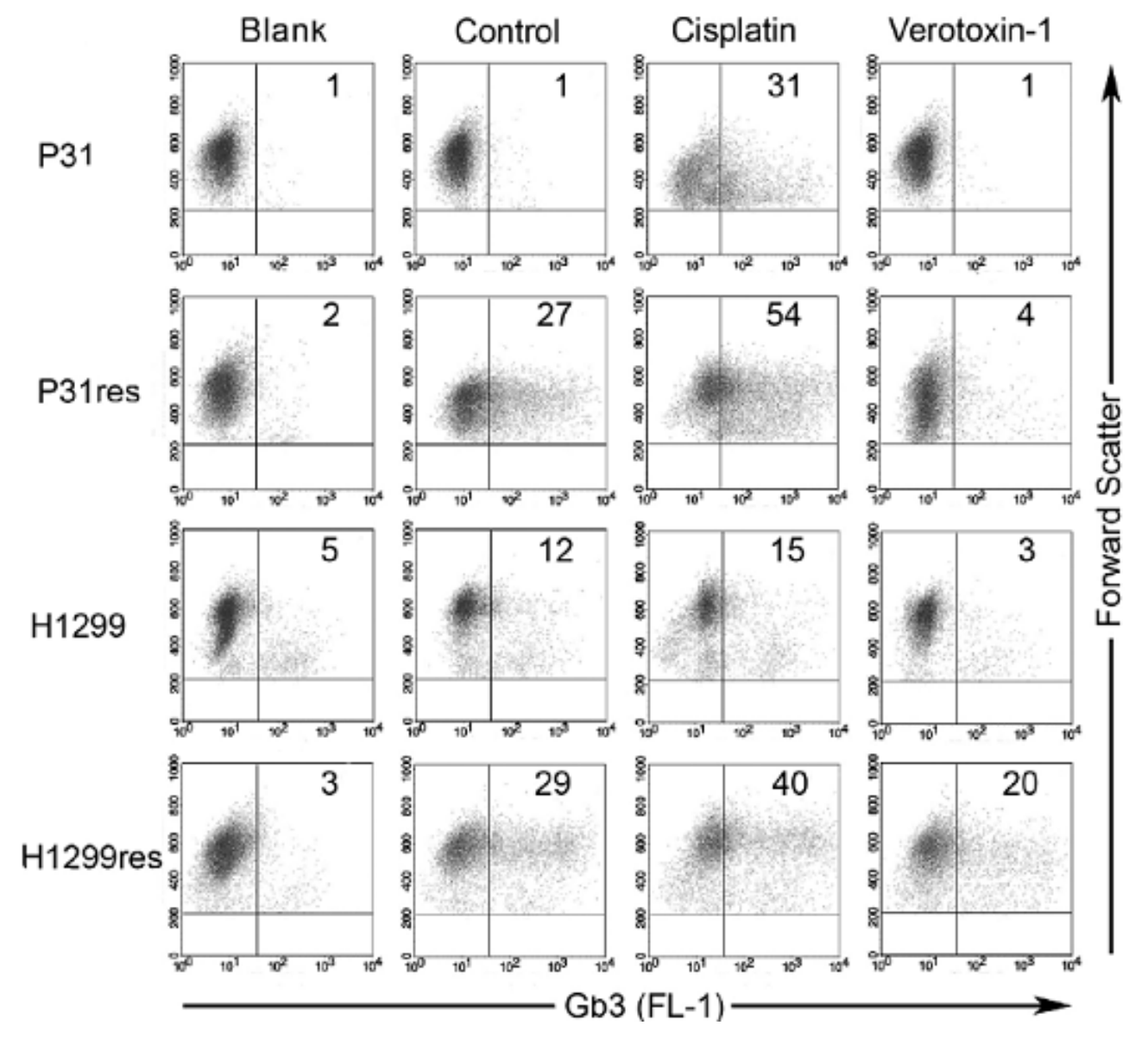


The MAPK pathway is involved in proapoptotic signaling of VT-1 in stressed cell systems and the pathway is also involved in cisplatin-induced apoptosis and induced cisplatin resistance $[15,80]$. Targeting the MAPK signaling pathway could, therefore, be an additional way to reduce cisplatin-induced tumor cells resistance.

The partial cell surface co-localization of Gb3/MDR1, the modulation of MDR1 cell surface expression by GSL and the possibility to inhibit MDR1 expression by VT-1/VT-1 B-subunit, all indicate a functional link between Gb3 and MDR1. Targeting the physiological regulation of MDR1 could be an efficient way not only to prevent the development of drug resistance during cancer chemotherapy but also to reverse inherent and acquired drug resistance of cancers.

\section{Acknowledgements}

We would like to thank the Lions foundation, the Swedish Cancer Society, the County Council, and the Faculty of Medicine, Umea University, for funding.

\section{References}

1. Cohen, A.; Hannigan, G.E.; Williams, B.R.; Lingwood, C.A. Roles of globotriosyl- and galabiosylceramide in verotoxin binding and high affinity interferon receptor. J. Biol. Chem. 1987, 262, 17088-17091.

2. $\quad$ Lingwood, C.A.; Law, H.; Richardson, S.; Petric, M.; Brunton, J.L.; De Grandis, S.; Karmali, M. Glycolipid binding of purified and recombinant Escherichia coli produced verotoxin in vitro. J. Biol. Chem. 1987, 262, 8834-8839.

3. Jacewicz, M.; Feldman, H.A.; Donohue-Rolfe, A.; Balasubramanian, K.A.; Keusch, G.T. Pathogenesis of Shigella diarrhea. XIV. Analysis of Shiga toxin receptors on cloned HeLa cells. J. Infect. Dis. 1989, 159, 881-889.

4. Lindberg, A.A.; Brown, J.E.; Strömberg, N.; Westling-Ryd, M.; Schultz, J.E.; Karlsson, K.A. Identification of the carbohydrate receptor for Shiga toxin produced by Shigella dysenteriae type 1. J. Biol. Chem. 1987, 262, 1779-1785.

5. Waddell, T.; Cohen, A.; Lingwood, C.A. Induction of verotoxin sensitivity in receptor-deficient cell lines using the receptor glycolipid globotriosylceramide. Proc. Natl. Acad. Sci. USA 1990, 87, 7898-7901.

6. Endo, Y.; Tsurugi, K.; Yutsudo, T.; Takeda, Y.; Ogasawara, T.; Igarashi, K. Site of action of a Vero toxin (VT2) from Escherichia coli O157:H7 and of Shiga toxin on eukaryotic ribosomes. RNA N-glycosidase activity of the toxins. Eur. J. Biochem. 1988, 171, 45-50.

7. Gariepy, J. The use of Shiga-like toxin 1 in cancer therapy. Crit. Rev. Oncol. Hematol. 2001, 39, 99-106.

8. O'Brien, A.D.; Tesh, V.L.; Donohue-Rolfe, A.; Jackson, M.P.; Olsnes, S.; Sandvig, K.; Lindberg, A.A.; Keusch, G.T. Shiga toxin: biochemistry, genetics, mode of action, and role in pathogenesis. Curr. Top. Microbiol. Immunol. 1992, 180, 65-94.

9. Olsnes, S.; Sandvig, K. How protein toxins enter and kill cells. Canc. Treat. Res. 1988, 37, 39-73. 
10. Raa, H.; Grimmer, S.; Schwudke, D.; Bergan, J.; Walchli, S.; Skotland, T.; Shevchenko, A.; Sandvig, K. Glycosphingolipid requirements for endosome-to-Golgi transport of Shiga toxin. Traffic 2009, 10, 868-882.

11. Sandvig, K.; Grimmer, S.; Lauvrak, S.U.; Torgersen, M.L.; Skretting, G.; van Deurs, B.; Iversen, T.G. Pathways followed by ricin and Shiga toxin into cells. Histochem. Cell Biol. 2002, 117, 131-141.

12. Saxena, S.K.; O'Brien, A.D.; Ackerman, E.J. Shiga toxin, Shiga-like toxin II variant, and ricin are all single-site RNA N-glycosidases of 28 S RNA when microinjected into Xenopus oocytes. J. Biol. Chem. 1989, 264, 596-601.

13. Kojio, S.; Zhang, H.; Ohmura, M.; Gondaira, F.; Kobayashi, N.; Yamamoto, T. Caspase-3 activation and apoptosis induction coupled with the retrograde transport of Shiga toxin: Inhibition by brefeldin A. FEMS Immunol. Med. Microbiol. 2000, 29, 275-281.

14. Johannes, L.; Römer, W. Shiga toxins-From cell biology to biomedical applications. Nat. Rev. Microbiol. 2010, 8, 105-116.

15. Johansson, D.; Andersson, C.; Moharer, J.; Johansson, A.; Behnam-Motlagh, P. Cisplatin-induced expression of Gb3 enables verotoxin-1 treatment of cisplatin resistance in malignant pleural mesothelioma cells. Br. J. Canc. 2010, 19, 383-391.

16. Derijard, B.; Raingeaud, J.; Barrett, T.; Wu, I.H.; Han, J.; Ulevitch, R.J.; Davis, R.J. Independent human MAP-kinase signal transduction pathways defined by MEK and MKK isoforms. Science 1995, 267, 682-685.

17. Han, J.; Lee, J.D.; Jiang, Y.; Li, Z.; Feng, L.; Ulevitch, R.J. Characterization of the structure and function of a novel MAP kinase kinase (MKK6). J. Biol. Chem. 1996, 271, 2886-2891.

18. Kim, B.J.; Ryu, SW.; Song, B.J. JNK- and p38 kinase-mediated phosphorylation of Bax leads to its activation and mitochondrial translocation and to apoptosis of human hepatoma HepG2 cells. J. Biol. Chem. 2006, 281, 21256-21265.

19. Walchli, S.; Skanland, S.S.; Gregers, T.F.; Lauvrak, S.U.; Torgersen, M.L.; Ying, M.; Kuroda, S.; Maturana, A.; Sandvig, K. The Mitogen-activated protein kinase p38 links Shiga Toxin-dependent signaling and trafficking. Mol. Biol. Cell 2008, 19, 95-104.

20. Lee, S.Y.; Cherla, R.P.; Tesh, V.L. Simultaneous induction of apoptotic and survival signaling pathways in macrophage-like THP-1 cells by Shiga toxin 1. Infect. Immun. 2007, 75, 1291-1302.

21. Johansson; D.; Johansson, A.; Grankvist, K.; Andersson, U.; Henriksson, R.; Bergström, P.; Brännström, T.; Behnam-Motlagh, P. Verotoxin-1 induction of apoptosis in Gb3-expressing human glioma cell lines. Canc. Biol. Ther. 2006, 5, 1211-1217.

22. Johansson, D.; Kosovac, E.; Moharer, J.; Ljuslinder, I.; Brännström, T.; Johansson, A.; Behnam-Motlagh, P. Expression of verotoxin-1 receptor Gb3 in breast cancer tissue and verotoxin-1 signal transduction to apoptosis. BMC Cancer 2009, 9, 67.

23. Jones, N.L.; Islur, A.; Haq, R.; Mascarenhas, M.; Karmali, M.A.; Perdue, M.H.; Zanke, B.W.; Sherman, P.M. Escherichia coli Shiga toxins induce apoptosis in epithelial cells that is regulated by the Bcl-2 family. Am. J. Physiol. Gastrointest. Liver Physiol. 2000, 278, G811-G819. 
24. Suzuki, A.; Doi, H.; Matsuzawa, F.; Aikawa, S.; Takiguchi, K.; Kawano, H.; Hayashida, M.; Ohno, S. Bcl-2 antiapoptotic protein mediates verotoxin II-induced cell death: Possible association between Bcl-2 and tissue failure by E. coli O157:H7. Genes Dev. 2000, 14, 1734-1740.

25. Erwert, R.D; Eiting, K.T.; Tupper, J.C.; Winn, R.K.; Harlan, J.M.; Bannerman, D.D. Shiga toxin induces decreased expression of the anti-apoptotic protein Mcl-1 concomitant with the onset of endothelial apoptosis. Microb. Pathog. 2003, 35, 87-93.

26. Janson, V.; Henriksson, R.; Grankvist, K. Acquisition of cisplatin-resistance in malignant mesothelioma cells reregulates pro-apoptotic BH3-only proteins. PhD Thesis, Umea University, Umea, Sweden, 2010, in preparation.

27. Janson, V.; Johansson, A.; Grankvist, K. Resistance to caspase-8 and -9 fragments in a malignant pleural mesothelioma cell line with acquired cosplatin-resistance. Cell Death Dis. 2010, 1, e78.

28. Erdmann, M.; Wipfler, D.; Merling, A.; Cao, Y.; Claus, C.; Kniep, B.; Sadick. H.; Bergler, W.; Vlasak, R.; Schwartz-Albiez, R. Differential surface expression and possible function of 9-O- and 7-O-acetylated GD3 (CD60 b and c) during activation and apoptosis of human tonsillar B and T lymphocytes. Glycoconj. J. 2006, 23, 627-638.

29. Alessandri, G.; De Cristan, G.; Ziche, M.; Cappa, A.P.; Gullino, P.M. Growth and motility of microvascular endothelium are modulated by the relative concentration of gangliosides in the medium. J. Cell Physiol. 1992, 151, 23-28.

30. Lahiri, S.; Futerman, A.H. The metabolism and function of sphingolipids and glycosphingolipids. Cell. Mol. Life Sci. 2007, 64, 2270-2284.

31. Schnaar, R.L. Glycolipid-mediated cell-cell recognition in inflammation and nerve regeneration. Arch. Biochem. Biophys. 2004, 426, 163-172.

32. Liu, Y.Y.; Gupta, V.; Patwardhan, G.A.; Bhinge, K.; Zhao, Y.; Bao, J.; Mehendale, H.; Cabot, M.C.; Li, Y.T.; Jazwinski, S.M. Glucosylceramide synthase upregulate Glucosylceramide synthase upregulates MDR1 expression in the regulation of cancer drug resistance through cSrc and beta-catenin signaling. Mol. Cancer 2010, 9, 145.

33. Okuda, T.; Tokuda, N.; Numata, S.; Ito, M.; Ohta, M.; Kawamura, K.; Wiels, J.; Urano, T.; Tajima, O.; Furukawa, K.; Furukawa, K. Targeted disruption of Gb3/CD77 synthase gene resulted in the complete deletion of globo-series glycosphingolipids and loss of sensitivity to verotoxins. J. Biol. Chem. 2006, 281, 10230-10235.

34. Lingwood, C.A.; Binnington, B.; Manis, A.; Branch, D.R. Globotriaosyl ceramide receptor function-Where membrane structure and pathology intersect. FEBS Lett. 2010, 3, 1879-1886.

35. Chen, J.K.; Capdevila, J.; Harris, R.C. Overexpression of C-terminal Src kinase blocks 14, 15-epoxyeicosatrienoic acid-induced tyrosine phosphorylation and mitogenesis. J. Biol. Chem. 2000, 275, 13789-13792.

36. Kazui, A.; Ono, M.; Handa, K.; Hakomori, S. Glycosylation affects translocation of integrin, Src, and caveolin into or out of GEM. Biochem. Biophys. Res. Commun. 2000, 273, 159-163.

37. Hakomori, S.; Zhang, Y. Glycosphingolipid antigens and cancer therapy. Chem. Biol. 1997, 4, 97-104.

38. Simons, K.; Ikonen, E. Functional rafts in cell membranes. Nature 1997, 387, 569-572. 
39. Lingwood, C.A. Aglycone modulation of glycolipid receptor function. Glycoconj. J. 1996, 13, 495-503.

40. Sandvig, K.; Garred, O.; van Helvoort, A.; van Meer, G.; van Deurs B. Importance of glycolipid synthesis for butyric acid-induced sensitization to Shiga toxin and intracellular sorting of toxin in A431 cells. Mol. Biol. Cell 1996, 7, 1391-1404.

41. Kovbasnjuk, O.; Edidin, M.; Donowitz, M. Role of lipid rafts in Shiga toxin 1 interaction with the apical surface of Caco-2 cells. J. Cell Sci. 2001, 114, 4025-4031.

42. Falguières, T.; Maak, M.; von Weyhern, C.; Sarr, M.; Sastre, X.; Poupon, M-F.; Robine, S.; Johannes, L.; Janssen, K-P. Human colorectal tumors and metastases express Gb3 and can be targeted by an intestinal pathogen-based delivery tool. Mol. Cancer Ther. 2008, 7, 2498-2508.

43. Smith, D.C.; Sillence, D.J.; Falguieres, T.; Jarvis, R.M.; Johannes, L.; Lord, J.M.; Platt, F.M.; Roberts, L.M. The association of Shiga-like toxin with detergent-resistant membranes is modulated by glucosylceramide and is an essential requirement in the endoplasmic reticulum for a cytotoxic effect. Mol. Biol. Cell 2006, 17, 1375-1387.

44. Falguieres, T.; Mallard, F.; Baron, C.; Hanau, D.; Lingwood, C.; Goud, B.; Salamero, J.; Johannes, L. Targeting of Shiga toxin b-subunit to retrograde transport route in association with detergent-resistant membranes. Mol. Biol. Cell 2001, 12, 2453-2468.

45. Römer, W.; Berland, L.; Chambon, V.; Gaus, K.; Windschiegl, B.; Tenza, D.; Aly, M.R.; Fraisier, V.; Florent, J.C.; Perrais, D.; Lamaze ,C.; Raposo, G.; Steinem, C.; Sens, P.; Bassereau, P.; Johannes, L. Shiga toxin induces tubular membrane invaginations for its uptake into cells. Nature 2007, 450, 670-675.

46. Khan, F.; Proulx, F.; Lingwood, C.A. Detergent-resistant globotriaosyl ceramide may define verotoxin/glomerular restricted hemolytic uremic syndrome pathology. Kidney Int. 2009, 75, 1135-1137.

47. Kang, E.; Rajpert-De Meyts, E.; Wiels J.; Skakkebæk, N.E. Expression of the glycolipid globotriaosylceramide (Gb3) in testicular carcinoma in situ. Virchows Arch. 1995, 426, 369-374.

48. LaCasse, E.C.; Bray, M.R.; Patterson, B.; Lim, W.M.; Perampalam, S.; Radvanyi, L.G.; Keating, A.; Stewart, A.K.; Buckstein, R.; Sandhu, J.S.; Miller, N.; Banerjee, D.; Singh, D.; Belch, A.R.; Pilarski, L.M.; Gariépy, J. Shiga-like toxin-1 receptor on human breast cancer, lymphoma, and myeloma and absence from CD34(+) hematopoietic stem cells: implications for ex vivo tumor purging and autologous stem cell transplantation. Blood 1999, 94, 2901-2910.

49. Arab, S.; Russel, E.; Chapman, W.B.; Rosen, B.; Lingwood, C.A. Expression of the verotoxin receptor glycolipid, globotriaosylceramide, in ovarian hyperplasias. Oncol. Res. 1997, 9, 553-563.

50. Kovbasnjuk, O.; Mourtazina, R.; Baibakov, B.; Wang, T.; Elowsky, C.; Choti, M.A.; Kane, A.; Donowitz, M. The glycosphingolipid globotriaosylceramide in the metastatic transformation of colon cancer. Proc. Natl. Acad. Sci. USA. 2005, 102, 19087-19092.

51. De Rosa, M.F.; Ackerley, C.; Wang, B.; Ito, S.; Clarke, D.M.; Lingwood, C. Inhibition of multidrug resistance by adamantylgb3, a globotriaosylceramide analog. J. Biol. Chem. 2008, 22, 4501-4511. 
52. Mattocks, M.; Bagovich, M.; De Rosa, M.; Bond, S.; Binnington, B.; Rasaiah, V.I.; Medin, J.; Lingwood, C. Treatment of neutral glycosphingolipid lysosomal storage diseases via inhibition of the ABC drug transporter, MDR1. Cyclosporin A can lower serum and liver globotriaosyl ceramide levels in the Fabry mouse model. FEBS J. 2006, 2739, 2064-2075.

53. Sikic, B.I. Modulation of multidrug resistance: A paradigm for translational clinical research. Oncology 1999, 13, 183-187.

54. Gottesman, M.M. Mechanisms of cancer drug resistance. Annu. Rev. Med. 2002, 53, 615-627.

55. Kourousis, C.; Kakolyris, S.; Androulakis, N.; Heras, P.; Vlachonicolis, J.; Vamvakas, L.; Vlata, M.; Hatzidaki, D.; Samonis, G.; Georgoulias, V. Salvage chemotherapy with paclitaxel, vinorelbine, and cisplatin (PVC) in anthracycline-resistant advanced breast cancer. Am. J. Clin. Oncol. 1998, 21, 226-232.

56. Bradley, G.; Ling, V. P-glycoprotein, multidrug resistance and tumor progression. Canc. Metastasis Rev. 1994, 13, 223-233.

57. Ueda, K.; Cornwell, M.M.; Gottesman, M.M.; Pastan, I.; Roninson, I.B.; Ling, V.; Riordan, J.R. The $m d r l$ gene, responsible for multidrug-resistance, codes for P-glycoprotein. Biochem. Biophys. Res. Commun. 1986, 141, 956-962.

58. Juliano, R.L.; Ling, V. A surface glycoprotein modulating drug permeability in Chinese hamster ovary cell mutants. Biochim. Biophys. Acta 1976, 455, 152-162.

59. Gottesman, M.M.; Pastan, I.; Ambudkar, S-V. P-glycoprotein and multidrug resistance. Curr. Opin. Genet. Dev. 1996, 6, 610-617.

60. Sandor, V.; Fojo, T.; Bates, S.E. Future perspectives for the development of P-glycoprotein modulators. Drug Resist. Updat. 1998, 1, 190-200.

61. Chaudhary, P.M.; Roninson, I.B. Induction of multidrug resistance in human cells by transient exposure to different chemotherapeutic drugs. J. Natl. Canc. Inst. 1993, 85, 632-639.

62. Sun, J.; He, Z.G.; Cheng, G.; Wang, S.J.; Hao, X.H.; Zou, M.J. Multidrug resistance P-glycoprotein: Crucial significance in drug disposition and interaction. Med. Sci. Mon. 2004, 10, RA5-RA14.

63. Mirski, S.E.; Cole, S.P. Multidrug resistance in small cell lung cancer. In Drug Resistance in Oncology; Bernal, S.D., Ed.; Marcel Dekker Inc.: New York, NY, USA, 1997; pp. 27-77.

64. Rudas, M.; Filipits, M.; Taucher, S.; Stranzl, T.; Steger, G.G.; Jakesz, R.; Pirker, R.; Pohl, G. Expression of MRP1, LRP and Pgp in breast carcinoma patients treated with preoperative chemotherapy. Breast Canc. Res. Treat. 2003, 81, 149-157.

65. Hyafil, F.; Vergely, C.; Du Vignaud, P.; Grand-Perret, T. In vitro and in vivo reversal of multidrug resistance by GF120918, an acridonecarboxamide derivative. Canc. Res. 1993, 53, 4595-4602.

66. Dantzig, A.H.; Shepard, R.L.; Cao, J.; Law, K.L.; Ehlhardt, W.J.; Baughman, T.M.; Bumol, T.F.; Starling, J.J. Reversal of P-glycoprotein-mediated multidrug resistance by a potent cyclopropyldibenzosuberane modulator, LY335979. Canc. Res. 1996, 56, 4171-4179.

67. Morjani, H.; Aouali, N.; Belhoussine, R.; Veldman, R.J.; Levade, T.; Manfait, M. Elevation of glucosylceramide in multidrug-resistant cancer cells and accumulation in cytoplasmic droplets. Int. J. Canc. 2001, 94, 157-165. 
68. Veldman, J.; Klappe, K.; Hinrichs, J.; Hummel, I.; van der Schaaf, G.; Sietsma, H.; Kok, J.; Altered sphingolipid metabolism in multidrug-resistant ovarian cancer cells is due to uncoupling of glycolipid biosynthesis in the Golgi apparatus. FASEB J. 2002, 16, 1111-1113.

69. Nicholson, K.; Quinn, D.; Kellett, G.; Warr, J. Preferential killing of multidrug-resistant KB cells by inhibitors of glucosylceramide synthase. Br. J. Canc. 1999, 81, 423-430.

70. De Rosa, M.F.; Sillence, D.; Ackerley, C.; Lingwood, C. Role of multiple drug resistance protein 1 in neutral but not acidic glycosphingolipid biosynthesis. J. Biol. Chem. 2004, 279, 7867-7876.

71. Pastan, I.; Gottesman, M.; Ueda, K.; Lovelace, E.; Rutherford, A.; Willingham, M. A retrovirus carrying an MDR1 cDNA confers multidrug resistance and polarized expression of P-glycoprotein in MDCK cells. Proc. Natl. Acad. Sci. USA 1988, 85, 4486-4490.

72. Shin, I.S.; Ishii, S.; Shin, J.S.; Sung, K.I.; Park, B.S.; Jang, H.Y.; Kim, B.W. Globotriaosylceramide (Gb3) content in HeLa cells is correlated to Shiga toxin-induced cytotoxicity and Gb3 synthase expression. BMB Rep. 2009, 31, 310-314.

73. Arab, S.; Rutka, J.; Lingwood, C. Verotoxin induces apoptosis and the complete, rapid, long-term elimination of human astrocytoma xenografts in nude mice. Oncol. Res. 1999, 11, 33-39.

74. Ishitoya, S.; Kurazono, H.; Nishiyama, H.; Nakamura, E.; Kamoto, T.; Habuchi, T.; Terai, A.; Ogawa, O.; Yamamoto, S. Verotoxin induces rapid elimination of human renal tumor xenografts in SCID mice. J. Urol. 2004, 171, 1309-1313.

75. Salhia, B.; Rutka, J.T.; Lingwood, C.; Nutikka, A; Van Furth, W.R. The treatment of malignant meningioma with verotoxin. Neoplasia 2002, 4, 304-311.

76. Johannes, L.; Decaudin, D. Protein toxins: intracellular trafficking for targeted therapy. Gene Ther. 2005, 12, 1360-1368.

77. El Alaoui, A.; Schmidt, F.; Amessou, M.; Sarr, M.; Decaudin, D.; Florent, J.C.; Johannes, L. Shiga toxin-mediated retrograde delivery of a topoisomerase I inhibitor prodrug. Angew. Chem. Int. Ed. Engl. 2007, 46, 6469-6472.

78. Vingert, B.; Adotevi, O.; Patin, D.; Jung, S.; Shrikant, P.; Freyburger, L.; Eppolito, C.; Sapoznikov, A.; Amessou, M.; Quintin-Colonna, F.; Fridman, W.H.; Johannes, L., Tartour, E. The Shiga toxin B-subunit targets antigen in vivo to dendritic cells and elicits anti-tumor immunity. Eur. J. Immunol. 2006, 36, 1124-1135.

79. Bast, D.J.; Sandhu, J.; Hozumi, N.; Barber, B.; Brunton, J. Murine antibody responses to the verotoxin $1 \mathrm{~B}$ subunit: demonstration of major histocompatibility complex dependence and an immunodominant epitope involving phenylalanine 30. Infect. Immun. 1997, 65, 2978-2982.

80. Brozovic, A.; Osmak, M. Activation of mitogen-activated protein kinases by cisplatin and their role in cisplatin-resistance. Canc. Lett. 2007, 251, 1-16.

(C) 2010 by the authors; licensee MDPI, Basel, Switzerland. This article is an open access article distributed under the terms and conditions of the Creative Commons Attribution license (http://creativecommons.org/licenses/by/3.0/). 